\title{
Field measurement of ground temperatures in Bandung: devices and the results of measurement
}

\author{
Muhammad Nur Fajri Alfata* and Amalia Nurjannah \\ Laboratory of Building Science, Research Institute for Housing and Human Settlements, Panyawungan, Cileunyi Wetan Street, \\ Bandung Regency, West Java, Indonesia
}

\begin{abstract}
Ground cooling is considered to be one of the passive cooling strategies in buildings although its application is rarely found in Indonesia. Effectiveness of this strategy depend on the ground temperature profiles. Meanwhile, comprehensive data of ground temperature as a basis of design for ground cooling are still rarely found in Indonesia. This research aims to develop the measurement devices for collecting ground temperatures data and to investigate the ground temperatures in different depths (i.e., $1 \mathrm{~m}, 2 \mathrm{~m}, \ldots, 9 \mathrm{~m}$ ). For measurement, an instrumentation system was developed with the main component of Arduino Mega 2560 as microcontroller. T-type thermocouples with diameter of $0,5 \mathrm{~mm}$ mounted in the metal cones were used as the temperature sensor and placed at the different depths. The field measurement was conducted from August to November 2019 in Bandung, West Java, Indonesia. This study demonstrated that the developed instrument system had good performance both in measuring and data acquisition. Model equation was developed to predict the ground temperature at certain depth regardless ground materials and humidity level. The results indicated that the ground temperature significantly lower to $5 \mathrm{~m}$-depth. However, the reduction of the temperature after $5 \mathrm{~m}$ was not significant; the deeper the ground, the temperature changes are negligible.
\end{abstract}

Keywords: microcontroller, ground cooling, data acquisition, temperature sensor, ground temperature

\section{Introduction}

Final energy consumption in Indonesia has increased from 0.59 billion $\mathrm{BOE}$ to 0.86 billion $\mathrm{BOE}$ in the last decade, which represents a 1.4-fold increase. In particular, the household sector was shared the largest part of energy consumption, which is around $37.8 \%$ of the total nationwide final energy consumption [1]. In order to reduce the energy consumption in the building without laying aside the indoor thermal performance, a number of researches were carried out [2-3]. One of the possible passive cooling techniques that has been broadly studied is ground cooling system.

Several studies showed that ground cooling system offers promising results in reducing energy consumption and at the same time improving the indoor thermal environments of the building. Sanusi et al. investigated the earth pipe cooling technology and reported that the system can reduce the air temperature by $6.4-6.9^{\circ} \mathrm{C}$. Thus, it has potential in providing low energy cooling in Malaysia through ground cooling [6]. In another study, it is found that for ambient temperature of close to $30^{\circ} \mathrm{C}$ in Germany, the outlet air temperature provided by this system were close to $18^{\circ} \mathrm{C}$ [7]. Compared to the conventional air conditioning system, ground temperature has a relatively constant temperature throughout the year which leads to a higher Coefficient of Performance (COP) [4]. By 2014, the ground cooling system especially
Ground-Coupled Heat Pump (GCHP) system have been installed in 49 countries and around USD 20 billion has been invested in this system [5].

To achieve the optimum performance of the ground cooling system, some parameters should be considered. Researchers found that the ground temperature is the most critical parameter that affecting the heat transfer of the ground cooling system and thermal storage for energy sources [8-10]. The ground temperature is used to provide cooled air for the building thank to the thermal property of the ground (i.e. heat capacity). Due to its property, it allows a damping of temperature fluctuations at different levels exponentially in respect to the soil depth [11]. In other words, the amplitude of the ground temperature decreases as ground depth increases. Therefore, it is important to investigate the ground temperature at various depths.

Ground temperature profiles have been investigated for different geographical locations and different techniques. In several studies, the ground thermal profiles were estimated using some techniques including numerical and geostatistical techniques [12]. Generally, the numerical technique uses numerical approach to estimate underground thermal properties and ground temperature profile such as Bland Altman analysis, Finite Element Method (FEM), Thermal-Response Test (TRT), etc. Meanwhile, geostatistical technique uses statistical

\footnotetext{
* Corresponding author: ariel.alfata@puskim.pu.go.id
} 
approach to estimate the ground temperature value such as Kriging method [13, 14]

Hence, it is obvious that the ground temperature data are required as a basis for designing a high-performance passive cooling system. In the context of Indonesia, comprehensive data of ground temperature are rarely found despite Indonesia has vast area (more than 1 million $\mathrm{km}^{2}$ ). Ideally, the measurement of ground temperature at the various locations with the different characteristics is required. This study aims to develop an affordable but reliable measurement device to measure ground temperature using Arduino Mega as main component. Moreover, this study also aims to investigate the ground temperatures using above instrument. By developing the device, the field measurement can be carried out separately at the same time in different places. By understanding profile of ground temperature, an optimum design of ground cooling can be achieved.

\section{Methods}

\subsection{Development of Instrumentation System}

In general, the instrument consists of three main systems; they are micro-controller, sensor, and acquisition data system. As can be seen in Figure 1, the instrumentation system was built by integrating Arduino Mega 2560 as micro-controller, T2105 as card reader, DS3231 as RealTime Clock, and 9 of MAX 31856 as thermocouple amplifier.

Algorithms for the device was implemented using Arduino IDE. These algorithms contained three different phases. At the first phase, the ground temperatures were measured by thermocouples as voltage values (analog signal). Secondly, this analog signal then sent to the MAX 31856 and directly being amplified and converted into digital signal. At the last stage, the digital signal then is processed by Arduino IDE to obtain the temperature value and then stored them into the memory card.
In this study, the Arduino Mega 2560 was used as the micro-controller. It was selected considering the requirement of board pins. Since the system used 9 amplifiers therefore it requires total of 36 digital pins and 4 digital pins for card reader and Real-Time Clock component. In addition, this selection also considered the requirement for bigger memory (i.e., SRAM: $8 \mathrm{~KB}$, EEPROM: $4 \mathrm{~KB}$ ) in order to continuously collect and process data for several months. Table 1 shows the detail specification of Arduino Mega 2560 used.

To measure ground temperature, a sensor is necessary. In this device, T-type thermocouple with diameter of $0.5 \mathrm{~mm}$ is used due to its stability and its excellent repeatability (see Table 1). T-type thermocouple has the higher accuracy than other thermocouple types with the special limits of error around $\pm 1^{\circ} \mathrm{C}$. Each thermocouple cable connected to the amplifier MAX 31856. All of the thermocouple cables were attached to metal cone designed specifically for measuring the ground temperature considering its high thermal conductivity which is around $78 \mathrm{~W} / \mathrm{mK}$ [15] (Figure 2). These metal cones were placed in the ground at the certain level of depth.

The other components including T2105 and DS3231 were connected directly to the digital and analog pins of Arduino (Figure1). In this study, all the ground temperature data were recorded every 10 minutes and stored in the memory card. To read and write the memory card, the T2105 was used as the card reader and writer hile DS3231-real time clock (RTC) was used as time variable for the measured data.

The MAX 31856 was used to amplify voltage signal received from the thermocouple. It is used to strengthen the signal and improve the precision of temperature sensing. Compared to the other amplifiers, this amplifier is much more stable and precise. This amplifier has been used for many years to measure temperature and gain reputation for its accuracy, repeatability and stability.

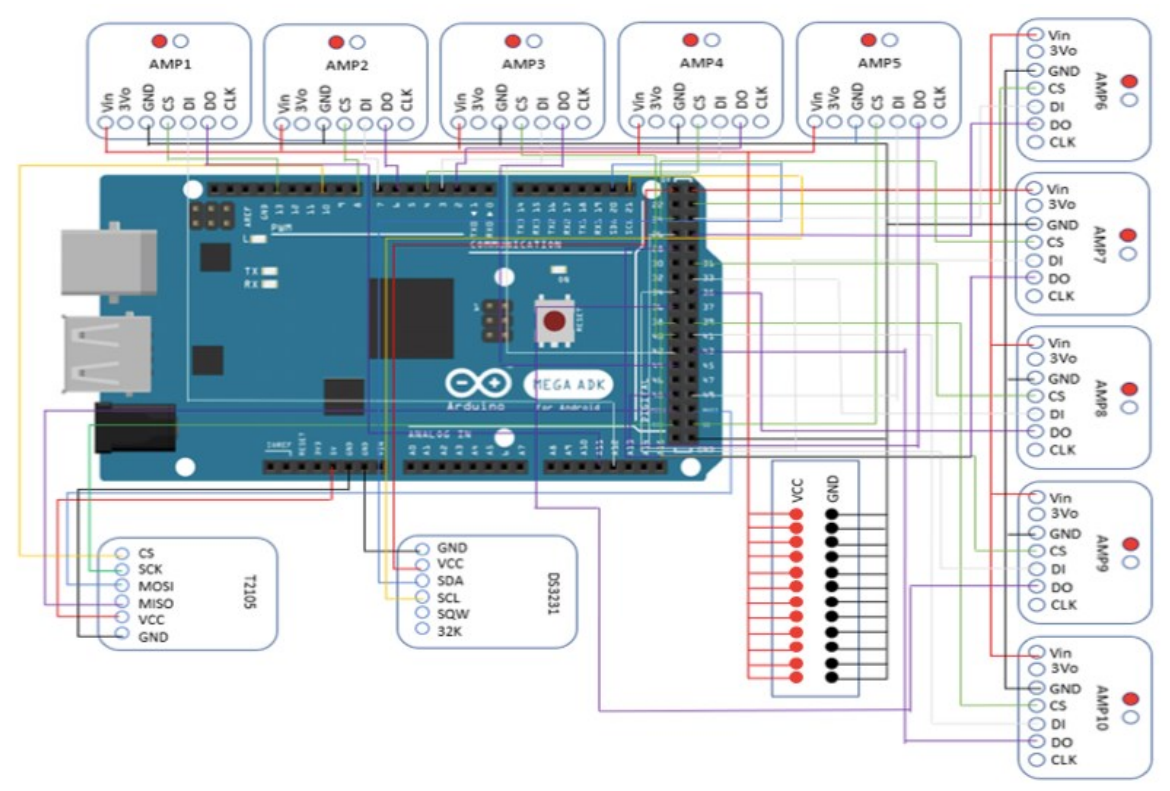

Fig. 1. Configuration of instrumentation components. 
Table 1. Spesification of Micro-Controller, Sensor, and Acquisition Data Devices

\begin{tabular}{|c|c|}
\hline Feature & Information \\
\hline \multicolumn{2}{|l|}{ Arduino } \\
\hline Operating voltage [V] & 5 \\
\hline Digital I/O Pins & 54 \\
\hline Analog Input Pins & 16 \\
\hline SRAM [KB] & 8 \\
\hline EEPROM [KB] & 4 \\
\hline Clock speed [MHz] & 16 \\
\hline \multicolumn{2}{|c|}{ T2105-micro SD card reader writer } \\
\hline Power supply [V] & 5 \\
\hline Current $[\mathrm{mA}]$ & 80 \\
\hline Interface power supply [V] & $3.3-5$ \\
\hline Card type & $\begin{array}{l}\text { Micro SD Card }(\leq 2 \mathrm{~GB}) / \text { Micro SDHC Card }(\leq \\
\text { 32GB) }\end{array}$ \\
\hline \multicolumn{2}{|l|}{ DS3231-real time clock } \\
\hline Operating voltage [v] & $2.3-5.5$ \\
\hline Operating temperature $\left[{ }^{\circ} \mathrm{C}\right]$ & -45 to +80 \\
\hline Clock accuracy $[\mathrm{ppm}]$ & $\begin{array}{l}+2 \text { to }-2 \text { for } 0^{\circ} \mathrm{C} \text { to } 40^{\circ} \mathrm{C} ;+3.5 \text { to }-3.5 \text { for }-40^{\circ} \mathrm{C} \\
\text { to }+85^{\circ} \mathrm{C}\end{array}$ \\
\hline Battery lifetime [years] & 3 \\
\hline \multicolumn{2}{|l|}{ T-Type Themocouple } \\
\hline Temperature range $\left[{ }^{\circ} \mathrm{C}\right]$ & $-270-370$ \\
\hline Accuracy $\left[{ }^{\circ} \mathrm{C}\right]$ & \pm 1 or $0.75 \%$ \\
\hline Limits of Error $\left[{ }^{\circ} \mathrm{C}\right]$ & \pm 0.5 or $0.4 \%$ \\
\hline Material & Copper/ Constantan \\
\hline \multicolumn{2}{|l|}{ MAX 31856} \\
\hline Thermocouple type & $\mathrm{K}, \mathrm{J}, \mathrm{N}, \mathrm{R}, \mathrm{S}, \mathrm{T}, \mathrm{E}$, or B type \\
\hline Temperature range $\left[{ }^{\circ} \mathrm{C}\right]$ & -210 to 1800 \\
\hline Operating voltage [V] & 5 \\
\hline
\end{tabular}

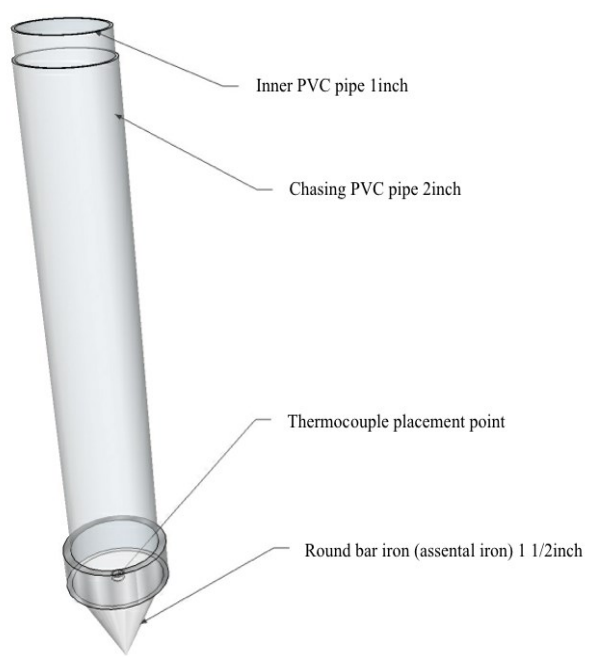

Fig. 2. Metal cone design.

\subsection{Procedures of Field Measurement}

Field measurement was carried out in the Laboratory of Building Sciences, Research Institute for Housing and Human Settlements, Bandung. Bandung is located in $6^{\circ} 54^{\prime} \mathrm{S}$ and $107^{\circ} 36^{\prime} \mathrm{E}$ and situated in the upland area (approximately $700 \mathrm{~m}$ above sea level). Although it has relatively lower average air temperature, Bandung receives relatively higher solar radiation compared to that received by the coastal area or lowland area due to its altitude. Thus, it is presumed that the surface in Bandung receives more heat from solar radiation.
Before installing the sensors into the depths, metal cones-attached thermocouples were tested by putting them into hot and cold water. This test aims to check whether the thermocouples showed the same readings or not and to ensure the reliability and the accuracy of the sensors.

The field measurement setup is illustrated in Figure 3. T-type thermocouples attached to the metal cones were placed at various depths from $1 \mathrm{~m}$ to $9 \mathrm{~m}$ (i.e., $1 \mathrm{~m}, 2 \mathrm{~m}, \ldots$, $9 \mathrm{~m})$. One inch and 2-inches PVS pipes were used as chasing to lay down the thermocouples into the ground. These sensors were connected to the control panel or control box where the micro-controller, amplifier MAX31856, T2105, and DS3231 RTC placed inside. The field measurement test was conducted over 3 months (i.e., August-November 2019) and the ground temperatures were measured and recorded at interval of 10 minutes.

\section{Results and Discussions}

\subsection{Development of Instrumentation System}

As previously discussed, the performance test mainly focused on the control system and sensor's accuracy. Performance test for the control system was conducted by analysing the algorithm sequence and made sure it works accordingly. In general, the control system demonstrated promising performance of measurement instrument. The evaluation of control algorithm indicated that the MAX 31856 performed very well in amplifying the received analog signal and converting it into digital signal. Then, the received digital signal were sent to the microcontroller. It is also appeared that the micro-controller smoothly synchronized to the other components and 


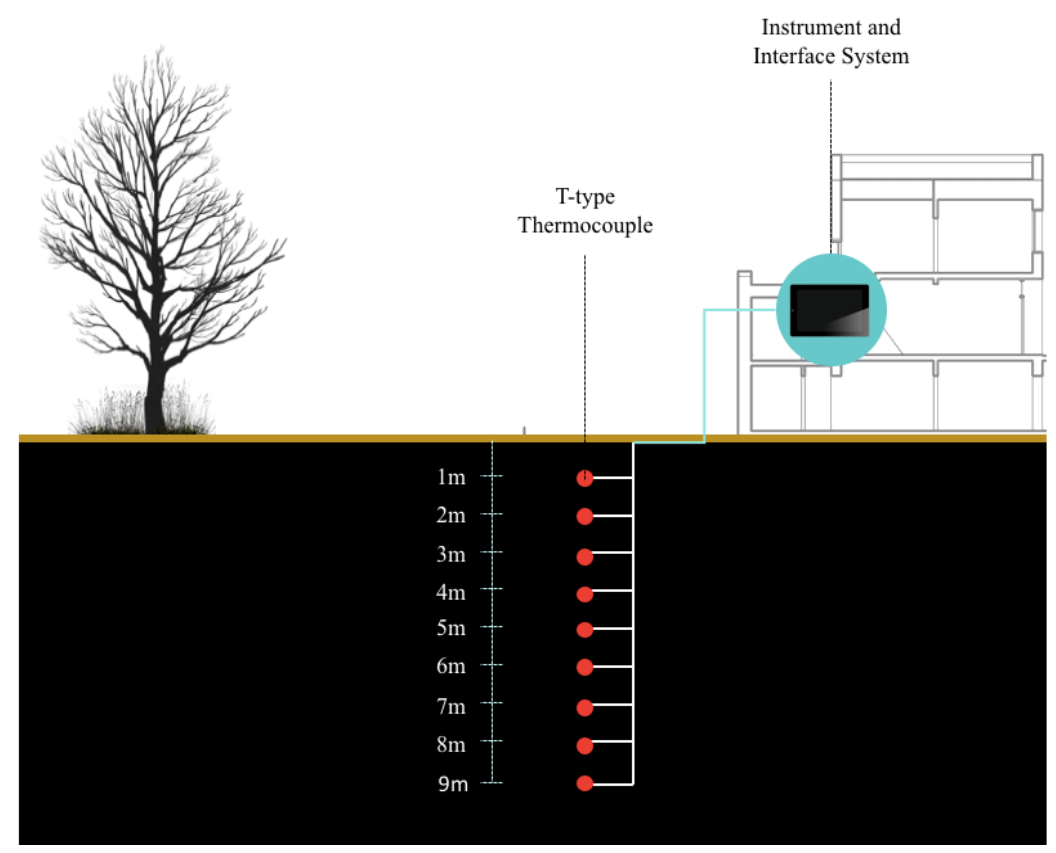

Fig. 3. Configuration of field measurement setup.

algorithm codes to obtain the ground temperature values. Based on the performance test, it is evidenced that the system including the wiring, programming codes between the micro-controller, MAX 31856, T2105, and DS3231 enabled to detect, read and store the ground temperatures without any significant interference and obstruction.

Sensor's accuracy is one of the parameters that must be considered in developing the device. It is the most important aspect of measuring. Therefore, the standard deviation of reading was used to evaluate the sensor performance and compared to the error limit of reading of

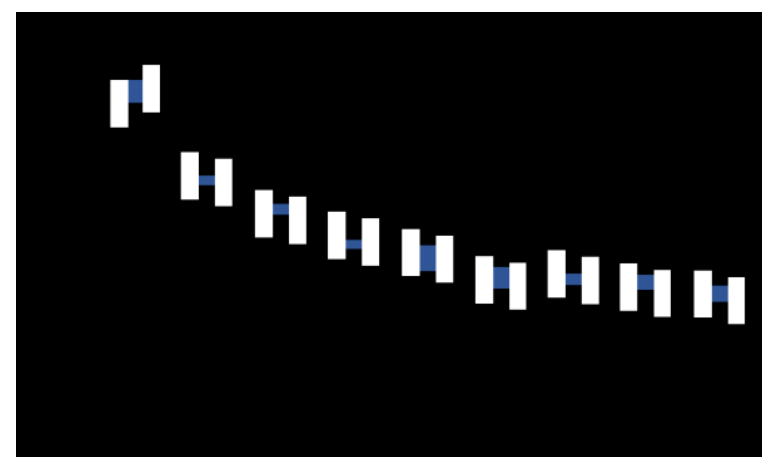

Fig. 4. Ground temperature profile of Bandung.

Table 2. Standard Deviation of Thermocouple

\begin{tabular}{|c|c|c|}
\hline Themocouple & Upper SD $\left({ }^{\circ} \mathbf{C}\right)$ & Lower SD $\left({ }^{\circ} \mathbf{C}\right)$ \\
\hline T1 & 0.3 & 0.2 \\
\hline T2 & 0.6 & 0.4 \\
\hline T3 & 0.9 & 0.1 \\
\hline T4 & 0.3 & 0.4 \\
\hline T5 & 0.4 & 0.6 \\
\hline T6 & 0.6 & 0.6 \\
\hline T7 & 0.3 & 0.8 \\
\hline T 8 & 0.3 & 0.5 \\
\hline T9 & 0.5 & 0.4 \\
\hline
\end{tabular}

the sensor. To comply the accuracy standard of T-type thermocouple, the maximum error limit of sensor must be around $\pm 1.0^{\circ} \mathrm{C}$ as the standard error of the sensor. Figure 4 present the ground temperature values from 9 T-type thermocouple at various depths. As indicated in Table 2, all of the thermocouples were fit to the error standard, with the standard deviation ranged from 0.1 to $0.9^{\circ} \mathrm{C}$. It means that the sensors can be used to measure the ground temperature accurately.

\subsection{Results of Field Measurement}

During the field measurement, the average outdoor air temperature was around $23.5^{\circ} \mathrm{C}$, while the minimum and maximum of air temperatures were around $16^{\circ} \mathrm{C}$ and $34^{\circ} \mathrm{C}$, respectively. Figure 4 and Figure 5 show the ground temperature profiles at the different levels of depth (ranged from $1 \mathrm{~m}$ to $9 \mathrm{~m}$ ) in Bandung. It is shown that the ground temperature decreased exponentially with depth. At the lowest level, the ground temperature reached $25.8^{\circ} \mathrm{C}$. The significant change of temperature can be seen until the depth level of $5 \mathrm{~m}$, in which the temperature decreased by $1.0^{\circ} \mathrm{C}$. Nonetheless, the ground temperature become more stable and constant at the depth of $6-9 \mathrm{~m}$, with the discrepancies ranged from $0.01^{\circ} \mathrm{C}$ to $0.1^{\circ} \mathrm{C}$. This is mainly because of the high thermal inertia of the ground depth level. The deeper ground level, the bigger thermal inertia so that it reduces the ground temperature fluctuation.

This finding is consistent with the previous researches that the temperature changes are negligible as the ground level of depth increase [9, 11,16]. This result also confirmed the research conducted by Andrarini et al. using simulation tool (i.e., EnergyPlus) to predict the ground temperature in Indonesia. This study showed that the ground temperature at the depth of $0.1 \mathrm{~m}$ on AugustNovember ranged between $27.5-28^{\circ} \mathrm{C}$ [17]. Compared to 


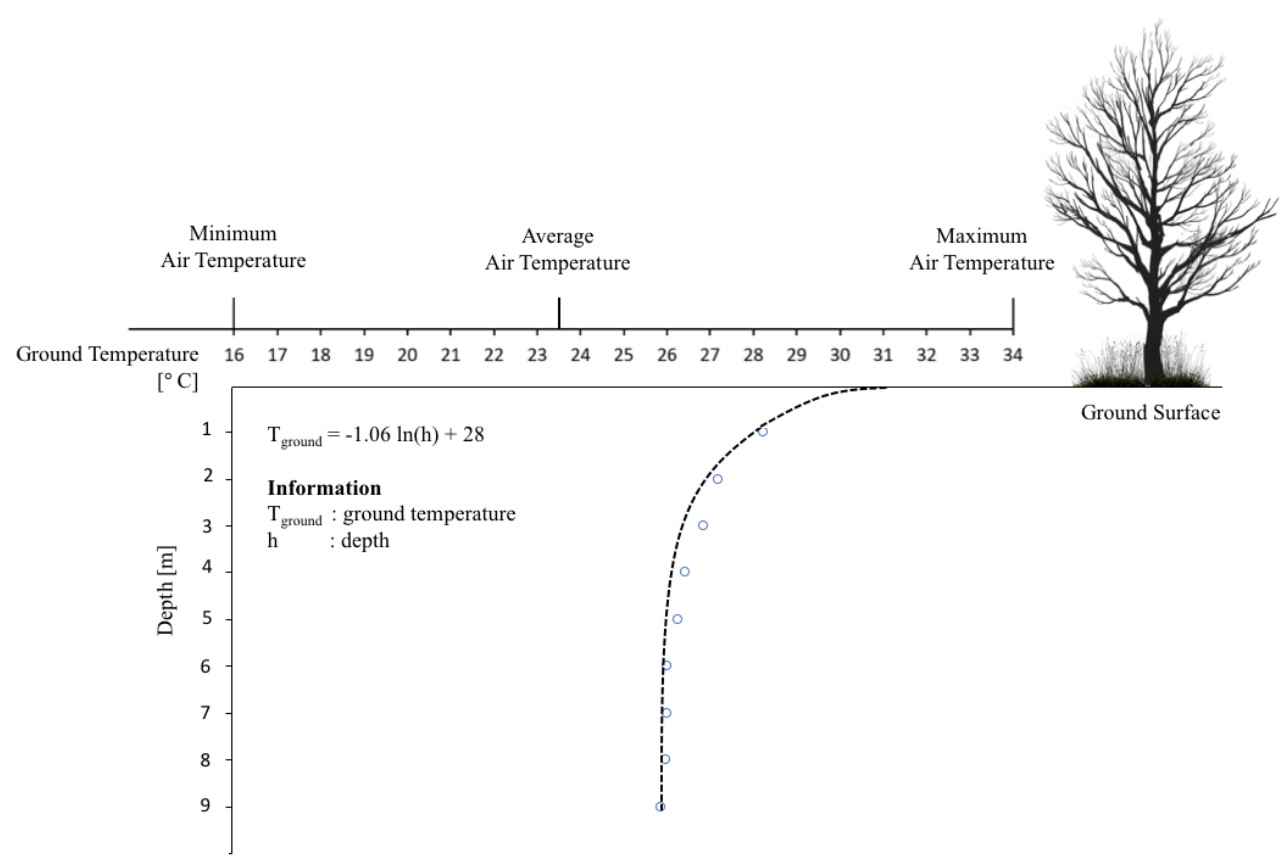

Fig. 5. Average ground temperature profile of Bandung at different level of depths.

this study, those values have small discrepancies most probably due to the high intensity of solar radiation received by the surface area in regard to its altitude $(768 \mathrm{~m}$ above sea level). From the measurement data, the ground temperature of Bandung can be represented by following equation:

$$
T_{\text {ground }}=-1.06 \ln (h)+28
$$

where $T_{\text {ground }}$ is ground temperature at $h$ level $\left({ }^{\circ} \mathrm{C}\right)$ and $h$ is depth $(\mathrm{m})$.

It should be noted that above equation was developed based on the ground level only regardless ground materials and humidity levels or water contents of ground. It is widely known that materials including ground and water have specific heat capacity that directly affecting the temperature. Therefore, the above equation might different if those factors are taken into account.

\section{Conclusions}

This study presents the result of development of measurement device to collect and record ground temperature and discusses the profile of ground temperature under different depths. In general, the measurement device consists of three main systems; they are micro-controller, sensors, and data acquisition system. Based on the field measurement, the developed system enabled to work properly according to the algorithm in detecting and reading the ground temperatures as well as storing them into device. From the test results, the data acquisition using T-type thermocouple and MAX 31656 as the sensor and its amplifier and converter was quite accurate, as indicated with the standard deviation of the thermocouples (lower than $\pm 1^{\circ} \mathrm{C}$ ). The metal cone was also found to perform in transmitting heat from the ground to the sensors.

From the field measurement, it is found that the ground temperature variations are prominent with discrepancies range from $0.2-1.0^{\circ} \mathrm{C}$ to a depth of approximately $5 \mathrm{~m}$. Due to its thermal inertia, the fluctuation of the ground temperatures is lowered as the ground depth level increased. Below the depth of $5 \mathrm{~m}$, its discrepancies ranged between $0.01-0.1^{\circ} \mathrm{C}$. the model equation to predict the ground temperature at different levels in Bandung is developed through this study. Using the equation, we can predict the ground temperature at certain depth level in Bandung. The method and instrumentation device that are developed in this work can be used to design and to optimize the ground cooling.

Nevertheless, the equation only valid for the dept level regardless ground material type and humidity level or water content. This study did not evaluate ground materials and humidity level at particular depth of ground, and therefore the model equation might be change if they are taken into account. Therefore, further investigation should be carried on in other regions with taking ground materials and humidity level into consideration.

By proper design of ground cooling system, it is expected that this relatively constant temperature at certain depth level $\left(25-26^{\circ} \mathrm{C}\right.$ at depth of $\left.5 \mathrm{~m}\right)$ can be utilized to cool the indoor space of buildings. In naturally ventilated buildings, it is difficult to achieve indoor air temperature at this level (i.e. $25-26^{\circ} \mathrm{C}$ ). In case of tropical regions, indoor air temperature sometime reached 30$32^{\circ} \mathrm{C}$ at the peak hours. With the different of $5-7^{\circ} \mathrm{C}$, this potential cannot be neglected. Therefore, design of ground cooling system should consider this finding in the future.

The authors would like to express sincere gratitude to Nugraha Budi Rahardja for his valuable comments, member of Division of Building Sciences for their kind support, and Research Institute for Housing and Human Settlements (Puskim), Ministry of Public Works and Housing for funding this research through National Budget (APBN). 


\section{References}

1. Ministry of Energy and Mineral Resources Republic of Indonesia, Handbook of Energy and Economic Statistics of Indonesia (2018).

2. R.Z. Freire, G.H. Oliveira and N. Mendes, Predictive Controller for Thermal Comfort Optimization and Energy Saving, Energy. Build. 40 (2008), pp 13531365.

3. A.Z. Sadeghifam, Combined Use of Design of Experiment and Dynamic Building Simulation in Assessment of Energy Efficiency in Tropical Residential Buildings, Energy Build. 86 (2015), pp 525-533.

4. Z. Linfeng, Z. Quan, L. Min, and D. Yaxing, A New Analytical Model for the Underground Temperature Profile under the Intermittent Operation for Ground Coupled Heat Pump System, Energy Procedia 75 (2015), pp 840-846.

5. A.N.Z. Sanusi, S. Li, N. Ibrahim, Passive Ground Cooling System for Low Energy Buildings in Malaysia (Hot and Humid Climates), Renew. Energy. pp 193-196.

6. J. Pfafferott, Evaluation of Earth to Air Heat Exchangers with a Standardised Method to Calculate the Energy Efficieny, Energy Build. 35 (2003), pp 971-983.

7. J.W. Lund and T.L. Boyd, Direct Utilization of Geothermal Energy 2015 Worldwide Review, in Proceedings World Geothermal Congress (2015), Melbourne, Australia.

8. T.R.H. Holmes, M. Owe, R.A.M. De Jeu, and H. Kooi, Estimating The Soil Temperature Profile from a Single Depth Observation: A Simple Empirical Heatflow Solution, Water Resour. Res. 44 (2008).
9. T.M. Yusof, S. Anuar, and H. Ibrahim, A Review of Ground Heat Exchangers for Cooling Aplication in the Malaysian Climate, J. Mech. Eng. Sci. 8 (2015), pp 1426-1439.

10. R.K. Singh and R.V. Sharma, Numerical Analysis for Ground Temperature Variation, Geotherm Energy 5 (2017).

11. A. Mukhtar, M. Z. Yusoff, and N.K. Ching, An Empirical Estimation of Underground Thermal Performance for Malaysian Climate, Journal of Physics: Conference Series (2017).

12. K. Jeong, T. Hong, M. Chae, J. Kim, M. Lee, C. Koo, and C. Ji, Development of The Hybrid Model for Estimating the Undisturbed Ground Temperature using the Finite Element Method and Geostatistical Technique, Energy. Build. 152 (2017), pp. 162-174.

13. T. Agemar, R. Schellschmidt, and S. Schutz, Subsurface Temperature Distribution in Germany, Geothermics 44 (2012), pp 65-77.

14. F. Sepulveda, M. Rosenberg, J. Rowland, and S. Simmons, Kriging Prediction of Drill-Hole Stratigraphy and Temperature Data from the Wairakei Geothermal Field, New Zealand: Implications for Conceptual Modelling," Geothermics 42 (2012), pp 13-31.

15. S. Szokolay, Introduction to Architectural Science: The Basis of Sustainable Design, Architectural Press, (2004).

16. G. Florides and S. Kalogirou, Measurements of Ground Temperature at Various Depths, Proceedings of the $3^{\text {rd }}$ International Conference on Sustainable Energy Technologies (2004).

17. R, Andarini, H. Schanzhofer, W. Stericher, and A.K. Pratiwi, Thermal Simulation and Cooling Energy Sensitivity Analysis of a Typical Shophouse in Jakarta, Indonesia, Building Simulation (2009) 